\title{
OCT1-Mediated Metformin Uptake Regulates Pancreatic Stellate Cell Activity
}

\author{
Chunhua Wu Shanhu Qiua Xiangyun Zhu ${ }^{a}$ Hao Lina Ling Lia \\ aDepartment of Endocrinology, Zhongda Hospital, Institute of Diabetes, Medical School, Southeast \\ University, Nanjing, China
}

\section{Key Words}

Metformin • Pancreatic stellate cells • Proliferation - Phosphorylated AMPK • Organic cation transporter member 1.

\begin{abstract}
Background/Aims: Metformin treatment is reported to be associated with a lower incidence of and mortality from pancreatic cancer (PC) in type 2 diabetes patients. Activated pancreatic stellate cells (PSCs) are key stroma cells responsible for pancreatic fibrogenesis and PC progression. However, little research is about the influence of metformin on PSCs. Given the potential beneficial effects of metformin on PC, pancreatic tumour stroma is an important target for new therapeutics. We observed the effects of metformin on PSCs. We investigated the effects of metformin on human PSCs proliferation and the production of extracellular matrix (ECM) proteins. Methods: Cells were cultured with different concentrations of metformin (0$10 \mathrm{mmol} / \mathrm{L})$. Cell proliferation was determined by immunofluorescence staining for nuclear Ki67 labelling. ECM production was studied by quantitative real-time polymerase chain reaction, immunoblotting and immunofluorescence microscopy. Adenosine monophosphateactivated protein kinase (AMPK), an important regulatory molecule responsible for metformin action, and the organic cation transporter member 1 (OCT1), which is believed to be the most important transporter for the pharmacological action of metformin, were investigated for their possible involvements in metformin-induced proliferation and ECM production. Results: Our results showed that metformin inhibited PSCs proliferation and decreased the production of ECM proteins by activation of AMPK phosphorylation. Silencing of OCT1 expression resulted in a reduction in the effects of metformin on PSCs activity. Conclusions: Collectively, the data indicate that OCT1 may contribute to uptake metformin and regulate PSCs activity. OCT1 is a target of metformin in regulating PSCs activity.

\section{Introduction}

Pancreatic cancer (PC) is characterized by a prominent stromal reaction. Pancreatic stellate cells (PSCs) have been found to play a key role in producing the pancreatic tumour stroma [1]. PSCs were first isolated and cultured by Apte [2] and Bachem in 1998 [3]. PSCs

Ling Li, PhD

KARGER
Department of Endocrinology, Zhongda Hospital, Southeast University

87 Dingjia Qiao Road, Nanjing 210009 (China)

Tel. +86-25-025-83272012, Fax +86-25-83272011, E-Mail dr_liling@126.com 


\section{Cellular Physiology Cell Physiol Biochem 2018;47:1711-1720 \begin{tabular}{c|c|c|} 
DOI: 10.1159/000491003 & O 2018 The Author(s). Published by S. Karger AG, Basel \\
www.karger.com/cpb
\end{tabular} \\ Wu et al.: Metformin Regulates Pancreatic Stellate Cell Activity}

represent $4-7 \%$ of all parenchymal cells in the normal pancreas and reside in close proximity to the basal aspect of pancreatic acinar cells. In health, PSCs are quiescent and characterized by the presence of vitamin A [2, 3]. In contrast to quiescent PSCs, activated PSCs lack cytoplasmic lipid droplets and long cytoplasmic processes, have the ability to proliferate and to synthesize extracellular matrix (ECM) proteins, including collagen and fibronectin. It is now well established that activated PSCs participate in the progression of PC, and PSCs are a new target for therapeutic strategies.

Therapeutic experimental trials have emerged to inhibit PSCs activation, including fat-soluble vitamins. Vitamin A and its metabolites were found to efficiently inhibit PSCs activation [4]. The vitamin E derivative alpha-tocopherol has been shown to selectively trigger activated PSCs death [5]. A recent study reported that vitamin D decreased PSCs activation [6].

Metformin as a common oral agent in the treatment of type 2 diabetes has been reported to be related to antineoplastic activity and reduced cancer burden such as PC [7]. Metformin is an unusually hydrophilic drug, and its transport involves an active uptake process via solute carrier organic transporters. The organic cation transporter member 1 (OCT1) is considered to be the most important transporter in the pharmacological action of metformin and is mainly expressed on the basolateral side of hepatocytes [8]. Shu et al. [9] demonstrated that OCT1 plays an important role in metformin therapeutic action, and Oct1 knockout mice reduced the glucose-lowering effect by reducing the intake of metformin. Adenosine monophosphate-activated protein kinase (AMPK) [10] is a nutrient and energy sensor that maintains energy homeostasis. Direct cellular effects of metformin involved the inhibition of ATP production and increased AMPK activity.

Metformin modulates the function of hepatic stellate cells (HSCs), which are similar to PSCs. Masayuki Adachi et al. [11] observed that metformin significantly inhibited plateletderived growth factor -stimulated proliferation of human HSCs via activation of AMPK. Metformin could also inhibit hepatocellular carcinoma angiogenesis by targeting HSCs through the AMPK pathway [12]. However, the influence of metformin on PSCs is not well known [13].

Therefore, this study was designed to determine the influence of metformin on PSCs proliferation and ECM production and the underlying molecular mechanism of the role that OCT1 plays in the action of metformin.

\section{Materials and Methods}

\section{Cell Isolation and Culture}

Human PSCs were obtained by outgrowth, using surgically resected pancreas, as described by Bachem [3]. Cells were grown in Dulbecco's modified Eagle's medium (DMEM)/Ham's F12 (1:1 v/v) (Gibco, USA) supplemented with $10 \%$ foetal bovine serum (Gibco, USA) and penicillin (100 units/ml), streptomycin $(0.1$ $\mathrm{mg} / \mathrm{ml}$ ) and were incubated at $37^{\circ} \mathrm{C}$ in $50 \mathrm{~mL} / \mathrm{L} \mathrm{CO}_{2}$ in a humidified atmosphere (Invitrogen, Karlsruhe, Germany). Cell purity was determined by staining with the marker desmin $(20 \%-40 \%), \alpha$-smooth muscle actin (> 90\%) and vimentin (100\%). The cells used were from passages 3-8.

\section{Western blot assay}

Cells were suspended in RIPA buffer containing a cocktail of protease inhibitors (Roche, USA). Determination of protein concentrations was done by a BCA assay (Keygen, China). Equal amounts of $5 \mu \mathrm{g}$ protein were separated by $8 \%$ or $10 \%$ SDS-PAGE and electrophoretically transferred onto polyvinylidene fluoride (PVDF) membranes (Millipore, Bedford, MA, USA). After blocking with 5\% nonfat milk or 5\% BSA dissolved in tris-buffered saline containing $0.1 \%$ Tween-20, the membrane was incubated with the indicated antibodies at $4^{\circ} \mathrm{C}$ overnight. Anti-collagen I, Anti-Fibronectin, Anti-SLC22A1 were all from Abcam company (Cambridge, MA, USA). Anti-phospho-AMPKa (Thr172) (Cell Signaling Technology, USA). The membranes were incubated with an appropriate HRP conjugated secondary antibody at room temperature for 1 hour. 


\section{Cellular Physiology Cell Physiol Biochem 2018;47:1711-1720 \begin{tabular}{l|l} 
DOI: 10.1159/000491003 & Ond Biochemistry 2018 The Author(s). Published by S. Karger AG, Basel \\
wublished onger.com/cpb
\end{tabular} \\ Wu et al.: Metformin Regulates Pancreatic Stellate Cell Activity}

Proteins were detected using an enhanced chemiluminescence reagent (Millipore, USA) and imaged by an Alpha Innotech Flour Chem-FC2 imaging system (Alpha Innotech, San Leanardo, CA). ImageJ (National Institutes of Health, USA) was used to quantify immunoblots.

Immunofluorescence.

Cells were grown on 24-well plates and were fixed with $4 \%$ formaldehyde (20 minutes), permeabilized with $0.1 \%$ Triton X-100 in PBS for 10 minutes, and then incubated in 5\% BSA (Keygen, China) for 1 hour to block non-specific protein-protein interactions. Cells were then incubated with the primary rabbit monoclonal antibodies to Ki-67 (Cell Signaling Technology, USA) or anti-human collagen I (Abcam, Cambridge, MA, USA) or rabbit anti-human fibronectin (Abcam, Cambridge, MA, USA) overnight at $4^{\circ} \mathrm{C}$, washed with PBS three times, treated with secondary antibodies (Abcam, Cambridge, MA, USA) for 1 hour, and washed with PBS three times. Cell nuclei were counterstained with 4, 6-diamidino-2-phenylindole (DAPI, Invitrogen,). Cells stained with the secondary antibodies alone were negative. Fluorescent signals were detected using an inverted microscope (Nikon, Japan) and photographs were taken. To compare different staining intensities, the laser intensity, background level, contrast, aperture, and electronic zoom size were always the same.

Real-time quantitative polymerase chain reaction ( $q P C R$ )

Total cellular RNA was extracted with TRIZOL(Invitrogen, California, USA) and RNA was reverse transcribed using $5 \times$ All-In-One MasterMix (ABM, Canada). qPCR was performed using an SYBR green method with a MasterMix buffer system. Gene expression was calculated with the comparative Ct method and normalized to the endogenous levels of GAPDH. Primer sequences used for qPCR were as follows: GAPDH-forward 5'-CCACCCATGGCAAATTCCATGGCA-3, reverse 5'-TCTAGACGGCAGGTCAGGTCCACC-3'; collagen I-forward 5'-AAAG-

AAGGCGG-CAAAGGT-3', reverse 5'-ACGATCACCACTC-TTG

CCA-3'; fibronectin-forward 5'-TCCAGGAGTTCACTGTGCC3', reverse 5'-CTGCAAG-

CCTTCAATAGTCA-3; OCT1-forward 5'-CTCATCACCATTGACCGCGT-3', reverse 5'-GCCCAACACCGCAAACAAAAT-3'.

Agarose gel electrophoresis of PCR products

Metformin transport involves an active uptake process via solute carrier organic transporters. There are three kinds of organic cation transporters: OCT1, OCT2 and OCT3, which has been reported in the transport of metformin. We also examined the expression of OCT1, OCT2 and OCT3 in PSCs. Primer sequences were as follows: OCT1- forward 5'-CTCATCACCATTGACCGCGT-3', reverse 5'-GCCCAACACCGCAAACAAAAT-3'; OCT2forward 5'-AATCTCTA-

CCCGCCTCCCTT-3', reverse 5'-CACAGAGCTCGTGAACCAGT-3'; OCT3- forward 5'-GTC ACCTTCGCCTTCCTCTT-3', reverse 5'-AGGTCAAACTCGCTGACGAT-3'. PCR products were examined by $1.5 \%$ agarose gel electrophoresis.

siRNAs and transfection

In an effort to understand the role of OCT1 in metformin action in the PSCs, siRNA against OCT1 (siOCT1) and nonspecific control siRNAs (siNC) were synthesized by Genepharma (Shanghai, China). The siRNA sequences were depicted as below:

siNC, sense 5'-UUCUCCGAACGUGUCACGUTT-3'and antisense 5'-ACGUGACACGUUCGGAGAATT-3'

siOCT1, sense 5'-GACCUGCACUGGUUAAACATT-3'and antisense 5'-UG UUUAACCAGUGCAGGUCTT-3'. In vitro transcription steps were according to the RNAi manual of Genepharma.

Statistical analysis

The results were presented as the means \pm SD of at least 3 independent experiments. Analysis with a one-way variance (ANOVA) was used to compare different groups, and a two-tailed Student t-test was used for comparison between 2 groups. $\mathrm{P}<0.05$ was considered to be statistically significant. All statistical analyses were performed using the SPSS 19.0 software (SPSS Inc., Chicago, IL). 


\section{Cellular Physiology Cell Physiol Biochem 2018;47:1711-1720

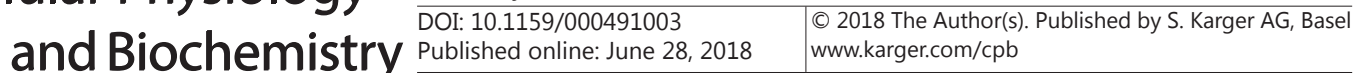 Wu et al.: Metformin Regulates Pancreatic Stellate Cell Activity}

\section{Results}

\section{Metformin Activated AMPK and Inhibited the Proliferation of PSCs}

Metformin effects are mainly mediated by the activation of AMPK, and therefore, we checked whether there was metformin activation of AMPK in PSCs. Treatment with metformin for 1 hour dose-dependently increased Thr-172 phosphorylation of $\alpha$-AMPK, which is necessary for AMPK activation [14] (Fig. 1A-B). Metformin inhibited PSCs proliferation, as measured by nuclear Ki67 labelling incorporation. Pretreatment with the AMPK inhibitor Compound C significantly abolished the inhibitory effect of metformin on PSCs proliferation (Fig. 2).

\section{Metformin inhibited the production of ECM}

qPCR of collagen type I mRNA and cellular fibronectin mRNA found that metformin inhibited the synthesis of collagen type I and cellular fibronectin. To show the influence of metformin on ECM protein expression, we added $5 \mathrm{mmol} / \mathrm{L}$ metformin to cultured PSCs, and performed Western blot assay of cell-associated collagen I and fibronectin. The results showed that there was a significant reduction after 72 hours of incubation with metformin. In addition, we measured collagen I and fibronectin by immunofluorescence staining. Compared with the control, the fluorescence intensity of collagen I and fibronectin was decreased in cultures receiving metformin. Pretreatment with the AMPK inhibitor Compound C significantly abolished the inhibitory effect of metformin on PSCs production of ECM (Fig. $3 \mathrm{~A}-\mathrm{C})$

OCT1 expression in PSCS, OCT1 efficiently silenced and decreased the phosphorylation of $A M P K$

To further study the possible mechanisms by which the activation of AMPK inhibited the proliferation and ECM production of PSCs, we identified whether OCT1 played a role in the action of metformin. We first found that PSCs expressed OCT1 (Fig. 4A-B). However, no OCT2 or OCT3 was observed in PSCs. To understand the effects of OCT1 in metformin in PSCs, we designed a siRNA targeting OCT1. We evaluated its gene silencing activity by qPCR. The expression of OCT1 was suppressed by approximately $80 \%$ by infection of PSCs with OCT1 siRNA, compared with a control siRNA (Fig. 4-C). The effect of gene silencing was confirmed

Fig. 1. Metformin activated AMPK. Serum-starved PSCs were treated with metformin for 60 minutes at the indicated concentrations (A-B). Western blot analysis was performed with the indicated antibodies. The results represented 3 individual experiments. ${ }^{* *} \mathrm{P}<0.01,{ }^{* * *} \mathrm{P}<0.001$.

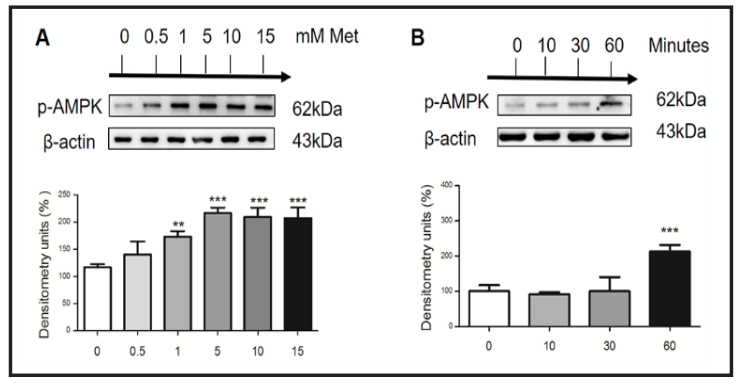

Fig. 2. Metformin inhibited the proliferation of PSCs via AMPK. After incubation with metformin ( $5 \mathrm{mM}$ ) for 72 hours, the AMPK inhibitor Compound C was preincubated 1 hour before treatment with metformin. DNA synthesis was assessed via ki-67 incorporation assay. The results represented 3 individual experiments. ${ }^{* *} \mathrm{P}<0.01$.

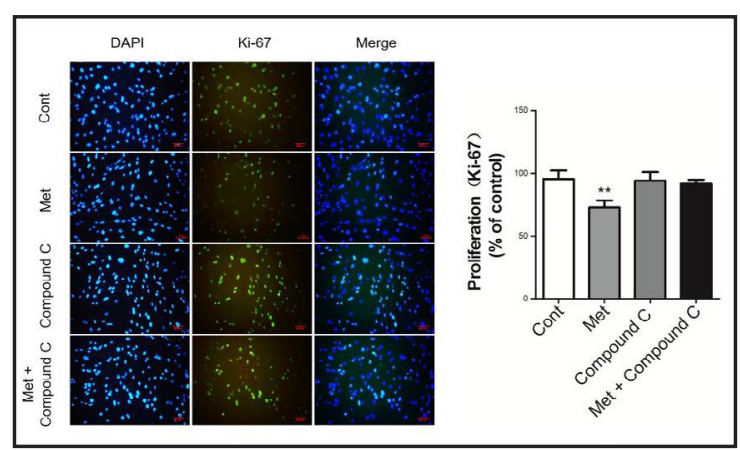


Fig. 3. Metformin inhibited ECM production via AMPK in PSCs. A. PSCs were incubated with metformin ( $5 \mathrm{mM})$ for 48 hours, and AMPK inhibitor Compound $\mathrm{C}$ was preincubated 1 hour before treatment with metformin, mRNA levels of the indicated genes were determined via qPCR. Data are expressed as the mean \pm SD of 3 individual experiments. $* * * \mathrm{P}<0.001$. B. PSCs were incubated with metformin $(5 \mathrm{mM})$ for 72 hours, and AMPK inhibitor Compound $\mathrm{C}$ was preincubated 1 hour before treatment with metformin. Western blot analysis was performed using the indicated

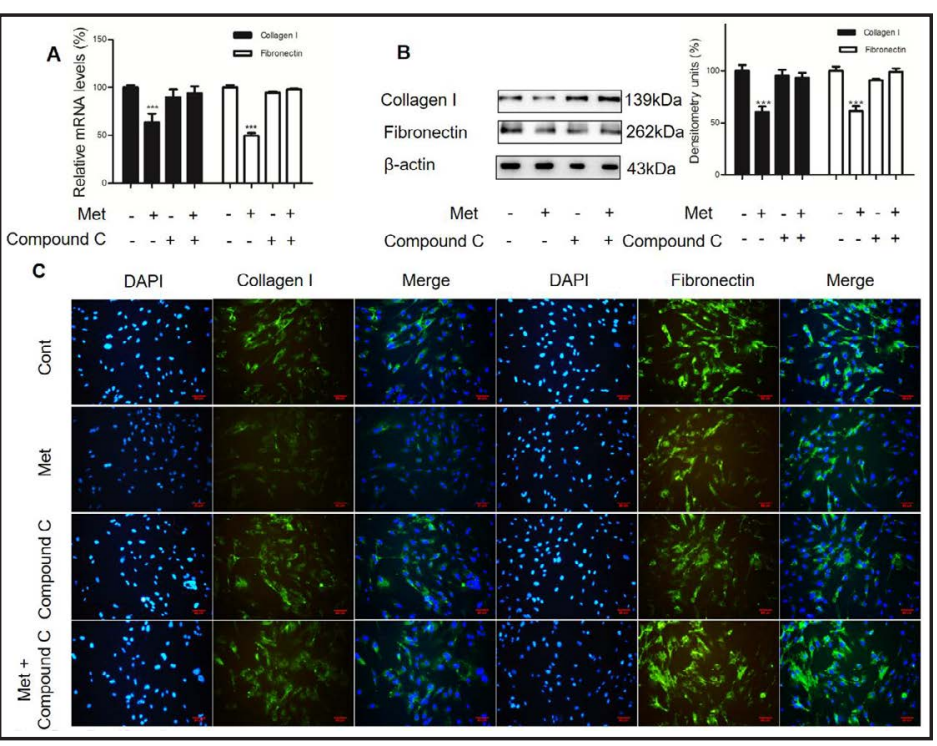
antibodies. The results represented 3 individual experiments. ${ }^{* * *} \mathrm{P}<0.001$. C. PSCs were incubated with metformin $(5 \mathrm{mM})$ for 72 hours, and AMPK inhibitor Compound $\mathrm{C}$ was preincubated 1 hour before treatment with metformin. Fluorescence micrographs analysis was performed using the indicated antibodies. The results represented 3 individual experiments.

Fig. 4. Expression of OCT1 in PSCs and OCT1 knockdown results in reduced phosphorylation of AMPK. A. Total RNA was extracted from three separate cell preparations and was amplified using PCR amplification. PCR products were run on $1.5 \%$ agarose gels. Lane 1 and lane 5 show molecularweight marker. Lane 2 and Lane 3 contained a PCR product for GAPDH from PSCs and LO2, respectively. Lane 6 and Lane 7 contained a PCR product for OCT1 from PSCs and LO2. Lane 4 and Lane 8 contained DEPC water but no cDNA as a negative control. B. Western blots showed PSCs expressing OCT1 protein. The OCT1 protein of LO2 as a positive control. C. After transfection with nonspecific

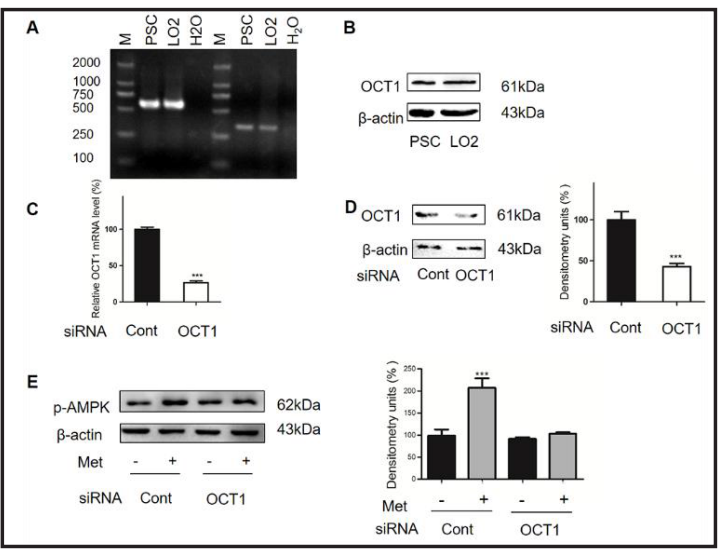
control siRNA, siRNA targeting OCT1, total mRNA was isolated and OCT1 mRNA expression analyzed by $\mathrm{qPCR}^{* * *} \mathrm{P}<0.001$. D. The protein levels of OCT1 were determined by Western blot analyses to assess the knockdown efficiency. The data shown are means \pm SD of three separate experiments. ${ }^{* * *} \mathrm{P}<0.001$. E. OCT1 knockdown results in reduced phosphorylation of AMPK. PSCs were infected with control-siRNA or OCT1siRNA for 6 hours, then treated with or without metformin for 1 hour. OCT1-RNAi reduced the metformininduced phosphorylation of AMPK in PSCs. The data shown are means \pm SD of three separate experiments. $* * * \mathrm{P}<0.001$.

at the protein level by Western blot (Fig. 4-D). As expected, active phosphorylation of AMPK by metformin was substantially reduced in OCT1 siRNA, in comparison with those in control siRNA (Fig. 4-E). Downstream, metformin-stimulated AMPK phosphorylation resulted in a decrease in PSCs proliferation and ECM production. The results suggested that the effect of metformin on AMPK in PSCs was modulated by OCT1. Thus, OCT1 appears to play a key role in determining one of the major pharmacologic effects of metformin, the inhibition of PSCs proliferation and ECM production. 
Fig. 5. OCT1 knockdown results in an attenuated metformin effect on PSCs. A. PSCs were infected with control-siRNA or OCT1-siRNA, treated with or without metformin for 72 hours. DNA synthesis was assessed via ki-67 incorporation assay. The results represented 3 individual experiments. ${ }^{*} \mathrm{P}<0.01$. B. PSCs were infected with controlsiRNA or OCT1-siRNA, treated with or without metformin for 48 hours, mRNA levels of the indicated genes were determined via qPCR. Data are expressed as the mean

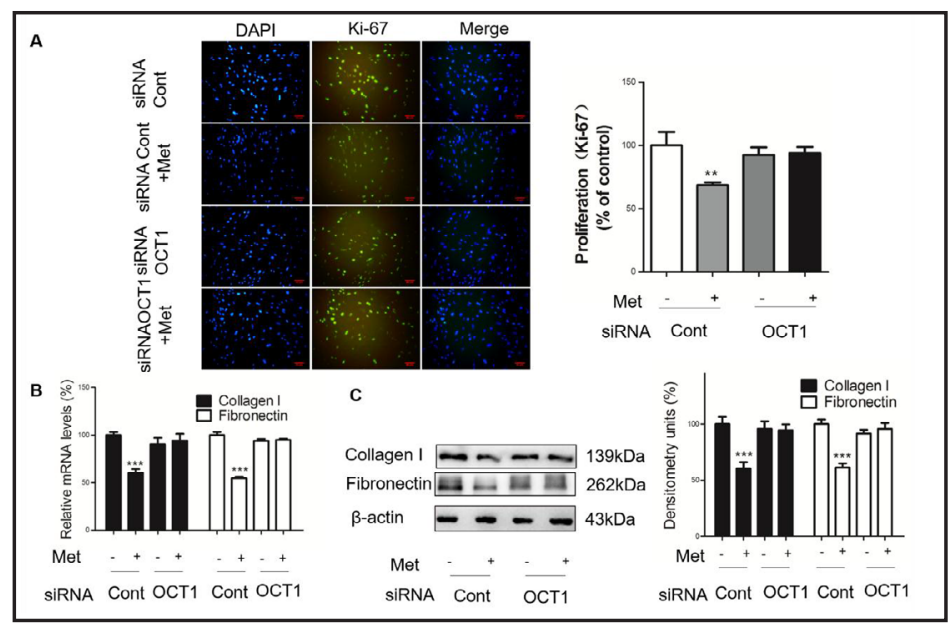
\pm SD of 3 individual experiments.

$* * * \mathrm{P}<0.001$. C. PSCs were infected with control-siRNA or OCT1-siRNA, treated with or without metformin for 72 hours, Western blot analysis was performed using the indicated antibodies. The results represented 3 individual experiments. ${ }^{* * *} \mathrm{P}<0.001$.

\section{OCT1 silencing resulted in an attenuated metformin effect on PSCs}

To further confirmed the function of OCT1, we next investigated whether OCT1 silencing affected the role of metformin in PSCs. Metformin inhibited PSCs proliferation, measured by Ki-67 staining, as compared to control. However, OCT1 silencing reversed metformininduced inhibition of PSCs proliferation (Fig. 5-A) We also detected collagen I and fibronectin in mRNA and protein levels, the results showed that OCT1 silencing reversed metformininduced inhibition of PSCs ECM production (Fig. 5B-C).

\section{Discussion}

Epidemiologic studies suggest that patients with diabetes who take metformin have a lower risk of developing or dying from PC $[7,15]$. PC is a devastating disease, and patient outcomes have not improved in decades. Treatments that target tumour cells have largely failed. Abundant desmoplasia is an important element of the tumour, and PSCs were found to produce the ECM proteins that compose the pancreatic tumour stroma [1]. PSCs activation is persistent in the tumour and results in a pathological matrix secretion leading to abundant desmoplasia, creating a physical barrier to therapy, as well as playing a role in innate drug resistance [16], leading to a poor clinical outcome in PC. With the identification of PSCs, researchers have paid more attention to the role of pancreatic tumour stroma in PC pathobiology. Recently, two studies have investigated the effect of metformin on tumour stroma. Joao Incio et al. [13] found that metformin alleviated the fibro-inflammatory microenvironment in obese/diabetic individuals with PC by reprogramming PSCs. Wanxing Duan et al. [17] found that metformin induction of AMPK activation represented a novel therapeutic approach for treating advanced PC through desmoplasia suppression. Although the beneficial effect of metformin in a mouse model of PC or in a patient of PC has been demonstrated, an in vivo study to evaluate the effect of AMPK activators on PSCs in pancreas fibrosis is difficult to design and interpret because the effect of AMPK activators can be attributed not only to PSCs but also to major effects on the cancer cell. In our study, we investigated PSCs in vitro. In view of our findings that metformin inhibits PSCs activity, we examined the effect of metformin on PSCs proliferation and the production of ECM. Our results showed that metformin prevented PSCs activation, as evidenced by a significantly inhibited PSCs proliferation; more importantly, a significant decrease was observed in the expression of the ECM collagen I and fibronectin, which were major components of fibrous tissue. Other

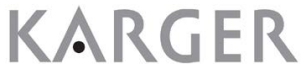


studies [18-21] have shown that metformin inhibited the proliferation of various types of tumour cells, including PC cells. In our study, we first found that metformin inhibited PSCs proliferation. Previous studies have shown that metformin has antifibrotic effects beyond its antihyperglycaemic and antitumour action. For example, Ting L et al. [22] have shown that treatment with metformin inhibited excessive ECM deposition in white adipose tissue of obese mice. Shen Y et al. [23] have found that metformin inhibited the activation of ERK signalling and attenuated the production of ECM proteins and collagen deposition in the obstructed kidneys. Moreover, one study [24] demonstrated that metformin attenuates cardiac fibrosis and vascular remodelling in obese rats. Our results were consistent with theirs.

Notably, we found that the above effects were associated with a significant increase in the activation of AMPK. AMPK is a highly conserved serine/threonine heterotrimeric protein kinase that consists of one catalytic $(\alpha)$ and two regulatory ( $\beta$ and $\gamma$ ) subunits [25] and is one of the major sites of metformin action. Metformin is transported into hepatocytes mainly through OCT1 and partially inhibits the mitochondrial respiratory-chain complex 1, resulting in reduced ATP levels and an accumulation of AMP. The change in the AMP/ATP ratio also activates AMPK, which suppresses lipid synthesis and exerts insulin-sensitizing effects [26]. However, the mechanisms of metformin for effects on glucose and lipid metabolism have differences. Some studies found AMPK was not essential for the effects of metformin on hepatic glucose output [27]. In contrast, AMPK activation was seem to be sufficient for metformin-induced lipogenic gene expression [28]. Metformin can also competitively inhibit the thiamine uptake via OCT1 and reduce TPP levels, which may lead to a lower energy status and activate AMPK [29]. So far, the precise mechanism leading to the activation of AMPK remains unclear.

Many studies have shown that there is metformin-mediated AMPK activation in all kinds of cells. One study [30] found that metformin inhibited breast cancer cell growth that was likely to be mediated by AMPK activation, in part by inhibition of fatty acid synthesis via ACC phosphorylation. Another study [31] demonstrated that metformin may protect against cisplatin-induced tubular cell apoptosis and AKI by stimulating AMPK $\alpha$ activation and autophagy induction in the tubular cells. Study by Ting Luo et al. [22] also found that metformin repressed the TGF- $\beta 1$-induced fibrogenic response via AMPK in vitro, which might account for the beneficial influences of metformin on fat fibrosis in obesity in vivo. The results of this study indicated that by activating AMPK phosphorylation, metformin potently inhibited PSCs proliferation and ECM production.

Organic cation transporters (OCTs) are responsible for the uptake and intracellular inactivation of a broad spectrum of endogenous substrates and for detoxification of xenobiotics and chemotherapeutics. Three organic cation transporters: OCT1, OCT2 and OCT3, which has been reported in the transport of metformin. In humans, OCT1 is mainly expressed in the liver and plays a role in the hepatic uptake of metformin [32]. Recent study indicated that [9] deletion of Oct1 resulted in a decrease in the effects of metformin on AMPK phosphorylation and gluconeogenesis. The study also showed the response to metformin was affected by changes in Oct1 expression and by the appearance of less functional variants. OCT2 is in the kidney and is associated with metformin uptake into renal epithelial cells [33]. OCT3 is widely distributed in many tissues including skeletal muscle, heart, brain and placenta [34, 35]. Our results provided the first evidence that PSCs expressed OCT1 but not OCT2 and OCT3. To find the function of OCT1, we chose OCT1 as an siRNA target to abolish OCT1 function. OCT1 silencing abolished the effect of metformin on the PSCs. The present study suggested that reduced OCT1-mediated metformin uptake was an important determinant of a poorer response to PSCs. Our results were consistent with study by Yan Shu et al. [9], deletion of Oct1 led to a decrease in the effects of metformin on AMPK phosphorylation. Yet, a study by Ligong Chen et al. [29] found that loss of OCT1 activated the AMPK in vivo. There were several possible reasons that might explain the discrepancies. First, Oct1 deficiency decreases expression levels of key metabolic transcription factors, including Creb1, Pgc1 $\alpha$, Crtc2, and Srebp1, possibly lead to activating AMPK. Second, Oct1 deletion 


\section{Cellular Physiology Cell Physiol Biochem 2018;47:1711-1720 \\ \begin{tabular}{c|c} 
DOI: 10.1159/000491003 & $\begin{array}{l}\text { O } 2018 \text { The Author(s). Published by S. Karger AG, Basel } \\
\text { www.karger.com/cpb }\end{array}$
\end{tabular} \\ Wu et al.: Metformin Regulates Pancreatic Stellate Cell Activity}

reducing TPP levels, may result in a lower energy status and activation of AMPK. Third, the influence factors in vivo are complex, AMPK activation may be caused by other factors, such as the increased rates of fatty acid oxidation in $O c t^{/-}$mice, it may result from reducing glycolysis, which causes increased AMP/ATP levels and activated AMPK. Furthermore, there is interest in the hypothesis that the OCTs may play an important role in the treatment of tumors. Michael Heise et al..[36] found the downregulation of OCT1 was related to tumor progression and poor prognosis in human hepatocellular carcinoma. Downregulation of OCT1 might lead to a worse or lacking response towards platin treatment. Beatrice Mohelnikova-Duchonova et al. [37] also found OCT1 was downregulated in PC, which was associated with angioinvasion. Yet, this study was limited to PC patients who underwent surgery. Whether the observed associations would have the same prognostic significance in patients with metastatic or advanced tumors remains to be determined. In addition, larger retrospective and prospective studies on PC patients are needed to confirm their results. In our study, we demonstrated that OCT1 is responsible for the PSCs uptake of metformin, loss of OCT1 may lead to PSCs uptake of metformin decreased, so the founction of metformin on PSCs is attenuated. However, the expression profiles of the OCTs in the PC patients whose treatment of metformin have not been reported, it needs to be defined in future.

The current findings enrich our understanding of the mechanism of metformin. As a metformin transporter, OCT1 is not only distributed in hepatocytes but also located in PSCs. OCT1 silencing causes metformin to have no effect on the increased activation of AMPK in PSCs; metformin-inhibited PSCs activity is abolished after OCT1 deletion.

Our study had limitations. The concentration range of metformin (0-10 $\mathrm{mM})$ used in this study was relatively narrow. The conventional antidiabetic dose used in humans was approximately $10 \mu \mathrm{M}$, but the doses used in these cells were higher; we showed direct antiproliferative actions of metformin at millimolar concentrations. Thus, further studies are needed to confirm the results. Moreover, we only focused on in vitro experiments.Oct1 $1^{-/-}$ mice or $\mathrm{Oct1}^{+/+}$mice with PC are needed to elucidate the mechanism leading to the activation of AMPK. Moreover, OCT1is expressed in liver cancer cell lines and the downregulation of OCT1 is associate with tumour progression and a worse patient survival [36]. OCT1 is also expressed in PC and the downregulation of OCT1 is related to angioinvasion [37]. In future studies, we should investigate the relationship between OCTs and PC that is treated with metformin.

In conclusion, our study is the first to investigate the effect of metformin on activated human PSCs. This study indicated that metformin inhibited PSCs proliferation and decreased the production of ECM proteins. Induction of PSCs quiescence was associated with an increase in activation of AMPK. Furthermore, we have demonstrated that OCT1 may have a dual role in metformin's pharmacologic effects in PSCs, serving as a transporter for metformin and as a target for metformin's effects on AMPK. It may represent a promising intervention as an antitumour agent via its ability to inhibit PSCs activity and consequently reduce the secretion of ECM proteins.

\section{Acknowledgements}

The authors would like to thank American journal experts for providing language help. Ling Li and Chunhua Wu conceived and designed the experiments, Chunhua Wu and Shanhu Qiu performed the experiments, Xiangyun Zhu and Hao Lin analyzed the data, Chunhua Wu and Shanhu Qiu wrote the paper.

\section{Disclosure Statement}

This research was supported by the National Natural Science Foundation of China (No 81570739). The authors declare to have no competing interests. 


\section{Cellular Physiology Cell Physiol Biochem 2018;47:1711-1720 \begin{tabular}{l|l} 
DOI: 10.1159/000491003 & Ond Biochemistry 2018 The Author(s). Published by S. Karger AG, Basel \\
Published online; June 28, 2018 & \begin{tabular}{l} 
www.karger.com/cpb \\
\cline { 2 - 3 }
\end{tabular}
\end{tabular}}

Wu et al.: Metformin Regulates Pancreatic Stellate Cell Activity

\section{References}

1 Apte MV, Park S, Phillips PA, Santucci N, Goldstein D, Kumar RK, Ramm GA, Buchler M, Friess H, McCarroll JA, Keogh G, Merrett N, Pirola R, Wilson JS: Desmoplastic reaction in pancreatic cancer: role of pancreatic stellate cells. Pancreas 2004;29:179-187.

2 Apte MV, Haber PS, Applegate TL, Norton ID, McCaughan GW, Korsten MA, Pirola RC, Wilson JS: Periacinar stellate shaped cells in rat pancreas: identification, isolation, and culture. Gut 1998;43:128-133.

-3 Bachem MG, Schneider E, Gross H, Weidenbach H, Schmid RM, Menke A, Siech M, Beger H, Grunert A, Adler G: Identification, culture, and characterization of pancreatic stellate cells in rats and humans. Gastroenterology 1998;115:421-432.

-4 McCarroll JA, Phillips PA, Santucci N, Pirola RC, Wilson JS, Apte MV: Vitamin A inhibits pancreatic stellate cell activation: implications for treatment of pancreatic fibrosis. Gut 2006;55:79-89.

5 Rickmann M, Vaquero EC, Malagelada JR, Molero X: Tocotrienols induce apoptosis and autophagy in rat pancreatic stellate cells through the mitochondrial death pathway. Gastroenterology 2007;132:2518-2532.

6 Blauer M, Sand J, Laukkarinen J: Physiological and clinically attainable concentrations of 1, 25-dihydroxyvitamin D3 suppress proliferation and extracellular matrix protein expression in mouse pancreatic stellate cells. Pancreatology 2015;15:366-371.

7 Li D, Yeung SC, Hassan MM, Konopleva M, Abbruzzese JL: Antidiabetic therapies affect risk of pancreatic cancer. Gastroenterology 2009;137:482-488.

8 Gong L, Goswami S, Giacomini KM, Altman RB, Klein TE: Metformin pathways: pharmacokinetics and pharmacodynamics. Pharmacogenet Genomics 2012;22:820-827.

-9 Shu Y, Sheardown SA, Brown C, Owen RP, Zhang S, Castro RA, Ianculescu AG, Yue L, Lo JC, Burchard EG, Brett CM, Giacomini KM: Effect of genetic variation in the organic cation transporter 1 (OCT1) on metformin action. J Clin Invest 2007;117:1422-1431.

10 Hardie DG, Ross FA, Hawley SA: AMPK: a nutrient and energy sensor that maintains energy homeostasis. Nat Rev Mol Cell Biol 2012;13:251-262.

-11 Adachi M, Brenner DA: High molecular weight adiponectin inhibits proliferation of hepatic stellate cells via activation of adenosine monophosphate-activated protein kinase. Hepatology 2008;47:677-685.

12 Qu H, Yang X: Metformin inhibits angiogenesis induced by interaction of hepatocellular carcinoma with hepatic stellate cells. Cell Biochem Biophys 2015;71:931-936.

13 Incio J, Suboj P, Chin SM, Vardam-Kaur T, Liu H, Hato T, Babykutty S, Chen I, Deshpande V, Jain RK, Fukumura D: Metformin Reduces Desmoplasia in Pancreatic Cancer by Reprogramming Stellate Cells and Tumor-Associated Macrophages. PLoS One 2015;10:e0141392.

14 Long YC, Zierath JR: AMP-activated protein kinase signaling in metabolic regulation. J Clin Invest 2006;116:1776-1783.

15 Sadeghi N, Abbruzzese JL, Yeung SC, Hassan M, Li D: Metformin use is associated with better survival of diabetic patients with pancreatic cancer. Clin Cancer Res 2012;18:2905-2912.

16 Straussman R, Morikawa T, Shee K, Barzily-Rokni M, Qian ZR, Du J, Davis A, Mongare MM, Gould J, Frederick DT, Cooper ZA, Chapman PB, Solit DB, Ribas A, Lo RS, Flaherty KT, Ogino S, Wargo JA, Golub TR: Tumour micro-environment elicits innate resistance to RAF inhibitors through HGF secretion. Nature 2012;487:500-504.

-17 Duan W, Chen K, Jiang Z, Chen X, Sun L, Li J, Lei J, Xu Q, Ma J, Li X, Han L, Wang Z, Wu Z, Wang F, Wu E, Ma Q, Ma Z: Desmoplasia suppression by metformin-mediated AMPK activation inhibits pancreatic cancer progression. Cancer Lett 2017;385:225-233.

18 Jiang X, Ma N, Wang D, Li F, He R, Li D, Zhao R, Zhou Q, Wang Y, Zhang F, Wan M, Kang P, Gao X, Cui Y: Metformin inhibits tumor growth by regulating multiple miRNAs in human cholangiocarcinoma. Oncotarget 2015;6:3178-3194.

19 Sesen J, Dahan P, Scotland SJ, Saland E, Dang VT, Lemarie A, Tyler BM, Brem H, Toulas C, Cohen-Jonathan Moyal E, Sarry JE, Skuli N: Metformin inhibits growth of human glioblastoma cells and enhances therapeutic response. PLoS One 2015;10:e0123721.

20 Tebbe C, Chhina J, Dar SA, Sarigiannis K, Giri S, Munkarah AR, Rattan R: Metformin limits the adipocyte tumor-promoting effect on ovarian cancer. Oncotarget 2014;5:4746-4764. 


\section{Cellular Physiology Cell Physiol Biochem 2018;47:1711-1720

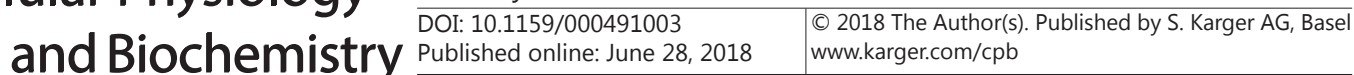 \\ Wu et al.: Metformin Regulates Pancreatic Stellate Cell Activity}

-21 Cai X, Hu X, Tan X, Cheng W, Wang Q, Chen X, Guan Y, Chen C, Jing X: Metformin Induced AMPK Activation, G0/G1 Phase Cell Cycle Arrest and the Inhibition of Growth of Esophageal Squamous Cell Carcinomas In vitro and In vivo. PLoS One 2015;10:e0133349.

22 Luo T, Nocon A, Fry J, Sherban A, Rui X, Jiang B, Xu XJ, Han J, Yan Y, Yang Q Li Q, Zang M: AMPK Activation by Metformin Suppresses Abnormal Extracellular Matrix Remodeling in Adipose Tissue and Ameliorates Insulin Resistance in Obesity. Diabetes 2016;65:2295-2310.

23 Shen Y, Miao N, Xu J, Gan X, Xu D, Zhou L, Xue H, Zhang W, Lu L: Metformin Prevents Renal Fibrosis in Mice with Unilateral Ureteral Obstruction and Inhibits Ang II-Induced ECM Production in Renal Fibroblasts. Int J Mol Sci 2016;17

24 Burla AK, Lobato NS, Fortes ZB, Oigman W, Neves MF: Cardiac fibrosis and vascular remodeling are attenuated by metformin in obese rats. Int J Cardiol 2013;165:483-487.

25 Steinberg GR, Kemp BE: AMPK in Health and Disease. Physiol Rev 2009;89:1025-1078.

-26 Foretz M, Guigas B, Bertrand L, Pollak M, Viollet B: Metformin: from mechanisms of action to therapies. Cell Metab 2014;20:953-966.

-27 Foretz M, Hebrard S, Leclerc J, Zarrinpashneh E, Soty M, Mithieux G, Sakamoto K, Andreelli F, Viollet B: Metformin inhibits hepatic gluconeogenesis in mice independently of the LKB1/AMPK pathway via a decrease in hepatic energy state. J Clin Invest 2010;120:2355-2369.

28 Zang M, Zuccollo A, Hou X, Nagata D, Walsh K, Herscovitz H, Brecher P, Ruderman NB, Cohen RA: AMPactivated protein kinase is required for the lipid-lowering effect of metformin in insulin-resistant human HepG2 cells. J Biol Chem 2004;279:47898-47905.

29 Chen L, Shu Y, Liang X, Chen EC, Yee SW, Zur AA, Li S, Xu L, Keshari KR, Lin MJ, Chien HC, Zhang Y, Morrissey KM, Liu J, Ostrem J, Younger NS, Kurhanewicz J, Shokat KM, Ashrafi K, Giacomini KM: OCT1 is a highcapacity thiamine transporter that regulates hepatic steatosis and is a target of metformin. Proc Natl Acad Sci U S A 2014;111:9983-9988.

- 30 Hadad SM, Hardie DG, Appleyard V, Thompson AM: Effects of metformin on breast cancer cell proliferation, the AMPK pathway and the cell cycle. Clin Transl Oncol 2014;16:746-752.

-31 Li J, Gui Y, Ren J, Liu X, Feng Y, Zeng Z, He W, Yang J, Dai C: Metformin Protects Against Cisplatin-Induced Tubular Cell Apoptosis and Acute Kidney Injury via AMPK $\alpha$-regulated Autophagy Induction. Sci Rep 2016;6:23975.

-32 Wang DS, Jonker JW, Kato Y, Kusuhara H, Schinkel AH, Sugiyama Y: Involvement of organic cation transporter 1 in hepatic and intestinal distribution of metformin. J Pharmacol Exp Ther 2002;302:510-515.

33 Dresser MJ, Leabman MK, Giacomini KM: Transporters involved in the elimination of drugs in the kidney: organic anion transporters and organic cation transporters. J Pharm Sci 2001;90:397-421.

34 Vialou V, Amphoux A, Zwart R, Giros B, Gautron S: Organic cation transporter 3 (Slc22a3) is implicated in salt-intake regulation. J Neurosci 2004;24:2846-2851.

-35 Zwart R, Verhaagh S, Buitelaar M, Popp-Snijders C, Barlow DP: Impaired activity of the extraneuronal monoamine transporter system known as uptake-2 in Orct3/Slc22a3-deficient mice. Mol Cell Biol 2001;21:4188-4196.

-36 Heise M, Lautem A, Knapstein J, Schattenberg JM, Hoppe-Lotichius M, Foltys D, Weiler N, Zimmermann A, Schad A, Grundemann D, Otto G, Galle PR, Schuchmann M, Zimmermann T: Downregulation of organic cation transporters OCT1 (SLC22A1) and OCT3 (SLC22A3) in human hepatocellular carcinoma and their prognostic significance. BMC cancer 2012;12:109.

-37 Mohelnikova-Duchonova B, Brynychova V, Hlavac V, Kocik M, Oliverius M, Hlavsa J, Honsova E, Mazanec J, Kala Z, Melichar B, Soucek P: The association between the expression of solute carrier transporters and the prognosis of pancreatic cancer. Cancer Chemother Pharmacol 2013;72:669-682. 